\title{
A Model of Growth Through Creative Destruction
}

\section{Citation}

Aghion, Philippe, and Peter Howitt. 1992. "A Model of Growth Through Creative Destruction." Econometrica 60, no. 2: 323-351.

\section{Published Version}

doi:10.3386/w3223

\section{Permanent link}

http://nrs.harvard.edu/urn-3:HUL.InstRepos:12490578

\section{Terms of Use}

This article was downloaded from Harvard University's DASH repository, and is made available under the terms and conditions applicable to Other Posted Material, as set forth at http:// nrs.harvard.edu/urn-3:HUL.InstRepos:dash.current.terms-of-use\#LAA

\section{Share Your Story}

The Harvard community has made this article openly available.

Please share how this access benefits you. Submit a story.

Accessibility 


\title{
A MODEL OF GROWTH THROUGH CREATIVE DESTRUCTION
}

\author{
By Philippe Aghion and Peter Howitt ${ }^{1}$
}

\begin{abstract}
A model of endogenous growth is developed in which vertical innovations, generated by a competitive research sector, constitute the underlying source of growth. Equilibrium is determined by a forward-looking difference equation, according to which the amount of research in any period depends upon the expected amount of research next period. One source of this intertemporal relationship is creative destruction. That is, the prospect of more future research discourages current research by threatening to destroy the rents created by current research. The paper analyzes the positive and normative properties of stationary equilibria, in which research employment is constant and GNP follows a random walk with drift, although under some circumstances cyclical equilibria also exist. Both the average growth rate and the variance of the growth rate are increasing functions of the size of innovations, the size of the skilled labor force, and the productivity of research as measured by a parameter indicating the effect of research on the Poisson arrival rate of innovations; and decreasing functions of the rate of time preference of the representative individual. Under laissez faire the economy's growth rate may be more or less than optimal because, in addition to the appropriability and intertemporal spillover effects of other endogenous growth models, which tend to make growth slower than optimal, the model also has effects that work in the opposite direction. In particular, the fact that private research firms do not internalize the destruction of rents generated by their innovations introduces a business-stealing effect similar to that found in the partial-equilibrium patent race literature. When we endogenize the size of innovations we find that business stealing also makes innovations too small.
\end{abstract}

KEYwORDS: Endogenous growth, innovations, creative destruction.

\section{INTRODUCTION}

THE MAIN CONTRIBUTION of the literature on endogenous growth pioneered by Romer (1986) and Lucas (1988) has been to endogenize the underlying source of sustained growth in per-capita income, namely the accumulation of knowledge. There are many channels through which societies accumulate knowledge, including formal education, on-the-job training, basic scientific research, learning by doing, process innovations, and product innovations. This paper examines a channel that has received little attention in the endogenous growth literature, namely that of industrial innovations which improve the quality of products.

This channel introduces into endogenous growth theory the factor of obsolescence; better products render previous ones obsolete. Obsolescence exemplifies an important general characteristic of the growth process, namely that progress creates losses as well as gains. It also embodies Schumpeter's idea of creative

\footnotetext{
${ }^{1}$ The authors wish to acknowledge the helpful comments and criticisms of Roland Bénabou, Olivier Blanchard, Patrick Bolton, Louis Corriveau, Mathias Dewatripont, Dick Eckaus, Zvi Griliches, Elhanan Helpman, Rebecca Henderson, Louis Phaneuf, William Scarth, Nancy Stokey, Patrick Rey, and the Co-Editor and referees of this journal.
} 
destruction (1942, p. 83, his emphasis):

\begin{abstract}
The fundamental impulse that sets and keeps the capitalist engine in motion comes from the new consumers' goods, the new methods of production or transportation, the new markets,.... [This process] incessantly revolutionizes the economic structure from within, incessantly destroying the old one, incessantly creating a new one. This process of Creative Destruction is the essential fact about capitalism.
\end{abstract}

The present paper constructs a simple model of growth through creative destruction, by modelling the innovation process as in the patent-race literature surveyed by Tirole (1988, Ch. 10) and Reinganum (1989). The expected growth rate of the economy depends upon the economy-wide amount of research. The paper shows that equilibrium in such an economy is determined by a forwardlooking difference equation, according to which the amount of research in any period depends upon the expected amount of research next period, similar to the difference equation that defines equilibrium in the two-period overlappinggenerations model of money (Azariadis (1981), Grandmont (1985)).

More specifically, the model assumes, following Schumpeter, that individual innovations are sufficiently important to affect the entire economy. A period is the time between two successive innovations. The length of each period is random, because of the stochastic nature of the innovation process, but the relationship between the amount of research in two successive periods can be modelled as deterministic. The amount of research this period depends negatively upon the expected amount next period, through two effects.

The first effect is that of creative destruction. The payoff from research this period is the prospect of monopoly rents next period. Those rents will last only until the next innovation occurs, at which time the knowledge underlying the rents will be rendered obsolete. Thus the expected present value of the rents depends negatively upon the Poisson arrival rate of the next innovation. The expectation of more research next period will increase that arrival rate, and hence will discourage research this period.

The second effect is a general equilibrium effect working through the wage of skilled labor, which can be used either in research or in manufacturing. In order to be consistent with the conditions for labor-market equilibrium, the expectation of more research next period must correspond to an expectation of higher demand for skilled labor in research next period, which implies the expectation of a higher real wage of skilled labor. Higher wages next period will reduce the monopoly rents that can be gained by exclusive knowledge of how to produce the best products. Thus the expectation of more research next period will discourage research this period by reducing the flow of rents expected to accrue to a successful innovator.

This functional relationship between research in two successive periods has a unique fixed point, which defines a stationary equilibrium. The stationary equilibrium exhibits balanced growth, in the sense that the allocation of skilled labor between research and manufacturing remains unchanged with each inno- 
vation; the log of GNP follows a random walk with drift. This is not always, however, the only equilibrium in the model. As in the overlapping-generations literature the functional relationship can also be satisfied by cyclical trajectories.

One noteworthy implication of the negative dependency of current research upon future research is the possible existence of what we call a "no-growth trap," a cyclical equilibrium in which the level of research oscillates deterministically between two levels each period, and in which the lower of these two levels is zero. An economy in such an equilibrium would stop growing in finite time, because with no research there would be no innovation, and hence the period with no research would never come to an end. The (rational) expectation that the next innovation would be followed by a very high level of research would discourage anyone from undertaking that innovation.

Another implication is that the average growth rate of the economy is not necessarily increased by an increase in the productivity of research. In particular, a parameter change that makes research more productive in some states of the world can discourage research in other states, by increasing the threat of obsolescence faced by the product of research in those other states, to such an extent that the average growth rate is reduced.

From a normative point of view, the average growth rate in stationary equilibrium may be more or less than socially optimal because of the presence of conflicting distortionary effects. Specifically, although the model includes the appropriability and intertemporal spillover effects which generate a less than optimal growth rate in Romer's (1990) model, it also has effects that work in the opposite direction. In particular, there is a "business-stealing" effect of the sort familiar from the patent-race literature (Tirole (1988, p. 399)). That is, researchers do not internalize the destruction of existing rents created by their innovations. When the size of innovations is taken as given, the business stealing effect can lead to too much growth. In addition, we find that when the size of innovations is endogenized, the business stealing effect tends to make innovations too small.

Other papers in the endogenous growth literature that model vertical product innovations include Segerstrom, Anant, and Dinopoulos (1990), who assume that the time between successive innovations is deterministic. They have a richer intersectoral structure than the present paper, and address a different set of questions. Stokey (1988) models vertical product innovations and obsolescence in a perfectly competitive model where innovations are the unintentional by-product of learning by doing. The cost-reducing innovations of Shleifer (1986) can also be interpreted as vertical product innovations. His model does not endogenize growth, however, except in a limited dichotomous sense; that is, the long-run average growth rate is fixed by the exogenously specified rate of invention, except in the singular case where no inventions are ever implemented and the economy stops growing.

Corriveau (1988) has a discrete-time analysis of endogenous growth based on cost-reducing innovations as in Shleifer, in which the possibility of simultaneous discoveries creates a different kind of "business-stealing" effect. In his model 
the payoff to current research is independent of future research because rents to innovations are assumed to accrue only in the same period as the research from which they resulted. Grossman and Helpman (1991) construct a model of vertical product innovation that explicitly integrates the analysis of Segerstrom, Anant, and Dinopoulos (1990) with that of the present paper.

Judd (1985) and Romer (1990) model growth based on horizontal product innovations, using the Dixit-Stiglitz (1977) model of product variety. These models involve no obsolescence; new products are no better than existing ones. They also involve no uncertainty. King and Rebelo (1988) introduce uncertainty into an endogenous growth model by assuming a random rate of return to the accumulation of human capital under conditions of perfect competition.

Within the patent-race literature the paper closest to the present is that of Reinganum (1985), which also emphasizes the affinity to creative destruction. The present paper adds to Reinganum's model the general equilibrium effects of future research on the rents created by current research, and of the level of manufacturing employment on the cost of research. The paper also generalizes the Reinganum model by allowing the stream of innovations to continue forever, and by explicitly analyzing the effect of the future level of research on the prospective reward to current research. ${ }^{2}$

Section 2 below presents the basic model of the paper. This basic model assumes for simplicity that each innovation creates an economy-wide monopoly in the production of intermediate goods. Section 3 derives the functional relationship between research in two successive periods that defines equilibrium. It then analyzes the determinants of the average growth rate and the variability of the growth rate in stationary equilibrium. One of those determinants is the degree of market power possessed by an intermediate-good monopolist, which is parameterized in the model. Section 4 characterizes the welfare properties of stationary equilibria in the basic model, under the assumption of a fixed size of innovations. Section 5 introduces the possibility of nondrastic innovations. Section 6 generalizes the model by allowing research firms to choose the size of innovations as well as their arrival rate. Section 7 deals with a strategic monopsony effect that has been ignored until this point in the argument, by which an intermediate firm can extend the expected lifetime of its monopoly by hiring more than the short-run profit-maximizing amount of skilled labor, at the cost of a higher real wage. Section 8 relaxes the assumption of a single economy-wide monopoly in the production of intermediate goods. Section 9 contains brief concluding remarks.

\footnotetext{
${ }^{2}$ That is, Reinganum's comparative-statics analysis follows the common practice of the patent-race literature in taking the reward to a successful innovation as given, whereas the following analysis shows that the effect of a parameter change on the time path of research involves feedback from future research to current research working through the two above-mentioned channels: creative destruction and the general equilibrium wage effect on profits, both of which flow through the reward to a successful innovation.
} 


\section{THE BASIC MODEL}

\section{A. Assumptions}

There are three classes of tradeable objects: labor, a consumption good, and an intermediate good. There is a continuum of infinitely-lived individuals, with identical intertemporally additive preferences defined over lifetime consumption, and the constant rate of time preference $r>0$. The marginal utility of consumption is assumed constant; thus $r$ is also the rate of interest.

There is no disutility from supplying labor. There are three categories of labor: unskilled labor, which can be used only in producing the consumption good; skilled labor, which can be used either in research or in the intermediate sector; and specialized labor, which can be used only in research. Each individual is endowed with a one-unit flow of labor. Let $M, N$, and $R$ denote respectively the mass of unskilled, skilled, and specialized individuals.

The consumption good is produced using the fixed quantity $M$ of unskilled labor, and the intermediate good, subject to constant returns. Since $M$ is fixed, the production function can be written as

$$
y=A F(x),
$$

where $F^{\prime}>0, F^{\prime \prime}<0, y$ is the flow output of consumption good, $x$ the flow of intermediate input, and $A$ a parameter indicating the productivity of the intermediate input.

The intermediate good is produced using skilled labor alone, according to the linear technology

$$
x=L,
$$

where $L$ is the flow of skilled labor used in the intermediate sector.

Research produces a random sequence of innovations. The Poisson arrival rate of innovations in the economy at any instant is $\lambda \phi(n, R)$, where $n$ is the flow of skilled labor used in research, $\lambda$ a constant parameter, and $\phi$ a constant-returns, concave production function. Both $\lambda$ and $\phi$ are given by the technology of research. There is no memory in this technology, since the arrival rate depends only upon the current flow of input to research, not upon past research. Assume that skilled labor is an essential factor in research: $\phi(0, R)=0$. Then an economy that allocates no skilled labor to research will not grow, because it will experience no innovations. (The "linear" case where $\phi(n, R)=n$, that is, where $R=0$, will be used frequently.)

Time is continuous, and indexed by $\tau \geqslant 0$. The subscript $t=0,1 \ldots$ denotes the interval starting with the $t$ th innovation (or with $\tau=0$ in the case of $t=0$ ) and ending just before the $t+1$ st. The length of each interval is random. All prices and quantities are assumed to remain constant within each interval. If $n_{t}$ is applied to research in interval $t$, the length of the interval will be exponentially distributed with parameter $\lambda \phi\left(n_{t}, R\right)$.

Each innovation consists of the invention of a new intermediate good, whose use as input allows more efficient methods to be used in producing the 
consumption good. Real-world examples include such "input" innovations ${ }^{3}$ as the steam engine, the airplane, and the computer, whose use made possible new methods of production in mining, transportation, and banking, with economywide effects. An innovation need not, however, be as revolutionary as these examples, but might consist instead of a new generation of intermediate good, similar to the old one.

Specifically, use of the new intermediate good increases the productivity parameter $A$ in (2.1) by the factor $\gamma>1$. There are no lags in the diffusion of technology. ${ }^{4}$ The most modern intermediate good is always produced, so that:

$$
A_{t}=A_{0} \gamma^{t}
$$$$
(t=0,1, \ldots)
$$

where $A_{0}$ is the initial value given by history. (Of course, it is always possible to produce the consumption good using an old technology, with a correspondingly old intermediate good.)

A successful innovator obtains a patent which it can use to monopolize the intermediate sector. (Section 8 relaxes this assumption by allowing for a finite number of monopolistic competitors.) The patent is assumed to last forever. However, the monopoly lasts only until the next innovation, at which time the intermediate good is replaced by the next vintage. All markets are perfectly competitive except that for intermediate goods.

\section{B. The Intermediate Monopolist's Decision Problem}

For ease of presentation the analysis starts by assuming that innovations are always drastic; that the intermediate monopolist is unconstrained by potential competition from the previous patent. This assumption will be relaxed in Section 5 below. The intermediate monopolist's objective is to maximize the expected present value of profits over the current interval. When the interval ends so do the profits. The only uncertainty concerns the length of the interval. Except in Section 7 below, the monopolist is assumed to take as given the amount of research at each time, and hence also takes as given the length of the interval.

\footnotetext{
${ }^{3}$ Scherer (1984) combines process- and input-oriented R and D into a measure of "used" $\mathrm{R}$ and $\mathrm{D}$, which he distinguishes from pure product $\mathrm{R}$ and $\mathrm{D}$. He estimates that during the period 1973-1978 in U.S. industry the social rate of return to "used" R and D lay between $71 \%$ and $104 \%$, whereas the return to pure product $R$ and $D$ was insignificant.

${ }^{4}$ Gradual diffusion could be introduced by allowing the productivity parameter after each innovation to follow a predetermined but gradual path asymptotically approaching the limit $A_{t}$, and then to jump to $A_{t}$ upon the next innovation and follow a gradual path approaching $A_{t+1}$. This would produce a cycle in research within each interval, as the gradual rise in productivity would induce manufacturing firms to hire more and more workers out of research until the next innovation occurs.
} 
Let $x_{t}$ be the flow of the intermediate good produced by the monopolist during interval $t$. By (2.2), $x_{t}$ also equals employment of skilled labor in manufacturing. The inverse demand curve facing a monopolist charging the price $p_{t}$ (relative to the numéraire consumption good) is the marginal product

$$
p_{t}=A_{t} F^{\prime}\left(x_{t}\right) \text {. }
$$

Thus the monopolist chooses $x_{t}$ to maximize $\left[A_{t} F^{\prime}\left(x_{t}\right)-w_{t}\right] x_{t}$, taking as given $A_{t}$ and the wage $w_{t}$ of skilled labor.

Define the "productivity-adjusted wage" as $\omega_{t} \equiv w_{t} / A_{t}$, and the "marginalrevenue function" as $\tilde{\omega}(x) \equiv F^{\prime}(x)+x F^{\prime \prime}(x)$. Assume that marginal revenue is downward-sloping and satisfies Inada-type conditions.

Assumption 1: $\tilde{\omega}^{\prime}(x)<0$ for all $x>0, \lim _{x \rightarrow 0} \tilde{\omega}(x)=\infty, \lim _{x \rightarrow \infty} \tilde{\omega}(x)=0$.

Then for any positive $\omega_{t}$ the monopolist's choice of output $x_{t}$ is given by the first-order condition

$$
\omega_{t}=\tilde{\omega}\left(x_{t}\right)
$$

or

$$
x_{t}=\tilde{x}\left(\omega_{t}\right),
$$

where $\tilde{x}$ is the function $\tilde{\omega}^{-1}$. The flow of monopoly profits is

$$
\pi_{t}=A_{t} \tilde{\pi}\left(\omega_{t}\right)
$$

where $\tilde{\pi}(\omega) \equiv-(\tilde{x}(\omega))^{2} F^{\prime \prime}(\tilde{x}(\omega))$. Note that $\tilde{x}$ and $\tilde{\pi}$ are each strictly positivevalued and strictly decreasing for all positive $\omega_{t}$.

An example satisfying Assumption 1 is the Cobb-Douglas example, in which the consumption-good technology is $F(x)=x^{\alpha}, 0<\alpha<1$, which yields

$$
p_{t}=w_{t} / \alpha, \quad \pi_{t}=\left(\frac{1-\alpha}{\alpha}\right) w_{t} x_{t}, \quad x_{t}=\left(\omega_{t} / \alpha^{2}\right)^{1 /(\alpha-1)} .
$$

\section{C. Research}

There are no contemporaneous spillovers in research; that is, a firm employing the amounts $z, s$ of the two factors in research will experience innovations with a Poisson arrival rate of $\lambda \phi(z, s)$, independently of the inputs of other firms. The objective of a firm in choosing $z$ and $s$ at each date is to maximize the flow of expected profits from research:

$$
\lambda \phi(z, s) V_{t+1}-w_{t} z-w_{t}^{s} s,
$$

where $V_{t+1}$ is the value of the $t+1$ st innovation, and $w_{t}^{s}$ is the wage rate of specialized labor. 
Because $\phi$ has constant returns, and because the total flow of specialized labor must equal $R$ in equilibrium, it follows from the Kuhn-Tucker conditions for maximizing (2.9) that

$$
w_{t} \geqslant \varphi^{\prime}\left(n_{t}\right) \lambda V_{t+1}, \quad n_{t} \geqslant 0, \quad \text { with at least one equality, }
$$

where $\varphi\left(n_{t}\right) \equiv \phi\left(n_{t}, R\right)$, and $n_{t}$ is the economy-wide flow of skilled labor used in research during interval $t$. Note that

$$
\varphi(0)=0, \quad \text { and } \quad \varphi^{\prime}(n)>0, \quad \varphi^{\prime \prime}(n) \leqslant 0 \text { for all } n \geqslant 0 .
$$

As we shall see, all research is conducted by outside research firms rather than by the incumbent monopolist. Because of constant returns to scale the number of research firms is indeterminate. The value $V_{t+1}$ to an outside research firm is the expected present value of the flow of monopoly profits $\pi_{t+1}$ generated by the $t+1$ st innovation over an interval whose length is exponentially distributed with parameter $\lambda \varphi\left(n_{t+1}\right)$ :

$$
V_{t+1}=\frac{\pi_{t+1}}{r+\lambda \varphi\left(n_{t+1}\right)}
$$

The reason why the monopolist chooses to do no research is that the value to the monopolist of making the next innovation would be $V_{t+1}-V_{t}$, which is strictly less than the value $V_{t+1}$ to an outside firm. This is an example of the Arrow effect, or replacement effect (see Tirole (1988, p. 392)). The efficiency effect, or rent-dissipation effect, according to which an outside firm might receive a smaller payoff from an innovation than would the present incumbent, because of having to compete with the present incumbent, is absent in the case of drastic innovations because the flow of profit $\pi_{t+1}$ in (2.12) is independent of whether the firm earning those profits has access to the previous patent. ${ }^{5}$

There is an important intertemporal spillover in this model. An innovation raises productivity forever. It allows each subsequent innovation to raise $A_{t}$ by the same multiple $\gamma$, and with the same probability $\lambda \varphi\left(n_{t}\right)$, but from a starting value that is higher by the multiple $\gamma$ than it would otherwise have been. The producer of an innovation captures (some of) the rents from that productivity gain, but only during one interval. After that the rents are captured by other innovators, building upon the basis of the present innovation, but without compensating the present innovator. ${ }^{6}$ This intertemporal spillover plays a role in the welfare analysis of Section 4 below.

\footnotetext{
${ }^{5}$ If, instead of a constant-returns research technology, each firm had an identical research technology with rising marginal cost, then the monopolist might do some research, but the Arrow effect would imply that the monopolist would do less research than each outside research firm, as shown by Reinganum (1985, Proposition 2) in a similar context.

${ }^{6}$ This is the spillover identified by Romer (1990, pp. S83-S85).
} 
The model also embodies Schumpeter's idea of "creative destruction." Each innovation is an act of creation aimed at capturing monopoly rents. But it also destroys the monopoly rents that motivated the previous creation. Creative destruction accounts for the term $\lambda \varphi\left(n_{t+1}\right)$ in the denominator of $V_{t+1}$ in (2.12). More research reduces the expected tenure of the current monopolist, and hence reduces the expected present value of its flow of rents.

\section{D. Capital Markets}

The structure of capital markets can be specified in many different ways. One is to suppose that there is a frictionless Walrasian credit market in which future expected consumption can be discounted at the constant rate $r$. Another is to suppose that there is no credit market. According to the latter specification all nonresearch workers consume their wage income at each instant, the owners of the monopoly intermediate firm consume their flow of profits at each instant, and research workers receive no pay unless their firms innovate, at which time they are paid in shares of the next intermediate firm. According to either specification, all research firms could be assumed to be owned by their workers, and (2.9) would represent the expected flow of surplus to be divided among them. The crucial assumption that utility is linear in consumption makes these different specifications all equivalent, by removing any motive to use capital markets for risk-sharing.

\section{PERFECT FORESIGHT DYNAMICS AND BALANCED GROWTH}

\section{A. Equilibrium}

At any point in time there is only one decision for society to make; namely, how to allocate the fixed flow $N$ of skilled labor between manufacturing and research. Combining (2.5), (2.7), (2.10), (2.12) and the equilibrium condition $N=n_{t}+x_{t}$ yields

$$
\frac{\tilde{\omega}\left(N-n_{t}\right)}{\lambda \varphi^{\prime}\left(n_{t}\right)} \geqslant \frac{\gamma \tilde{\pi}\left(\tilde{\omega}\left(N-n_{t+1}\right)\right)}{r+\lambda \varphi\left(n_{t+1}\right)}, \quad n_{t} \geqslant 0, \quad \text { with at least one equality. }
$$

Condition (3.1) determines research employment at $t$ as a function of research employment at $t+1$ :

$$
n_{t}=\psi\left(n_{t+1}\right),
$$

where $\psi:[0, N) \rightarrow \mathbb{R}_{+}$is a strictly decreasing function wherever it is positivevalued.

The functional relationship $\psi$ between research employment in two successive periods is illustrated in Figure 1, where $c\left(n_{t}\right)$ is the "marginal cost of 


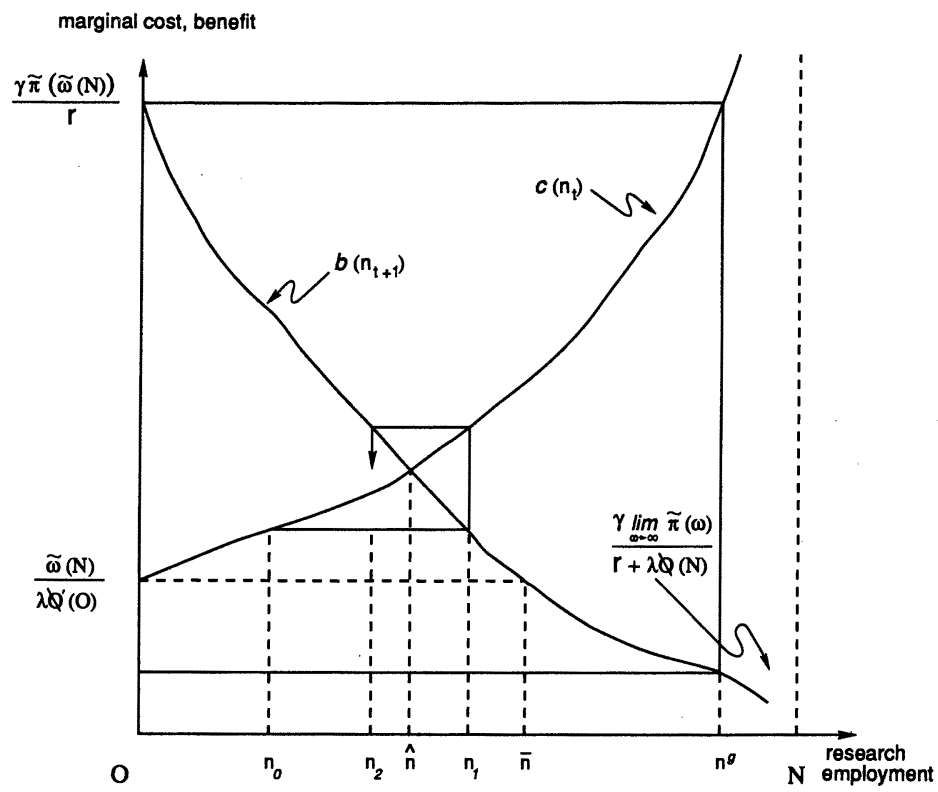

Figure 1.-The effect of future research on current research: $n_{0}=\psi\left(n_{1}\right)$ and $n_{1}=\psi\left(n_{2}\right)$. The pair $\left(0, n^{g}\right)$ constitutes a no-growth trap.

research" and $b\left(n_{t+1}\right)$ the "marginal benefit of research," defined by

$$
\begin{aligned}
& c\left(n_{t}\right) \equiv \frac{\tilde{\omega}\left(N-n_{t}\right)}{\lambda \varphi^{\prime}\left(n_{t}\right)}, \\
& b\left(n_{t+1}\right) \equiv \frac{\gamma \tilde{\pi}\left(\tilde{\omega}\left(N-n_{t+1}\right)\right)}{r+\lambda \varphi\left(n_{t+1}\right)} .
\end{aligned}
$$

By (2.11) and Assumption 1, $c$ is strictly increasing, $b$ is strictly decreasing, and $c\left(n_{t}\right) \rightarrow \infty$ as $n_{t} \rightarrow N$. It follows that in the case illustrated in Figure 1, where $c(0)<b(0), \psi\left(n_{t+1}\right)$ is well defined on [0,N), and is positive and decreasing if and only if ${ }^{7} n_{t+1}<\bar{n}$. In the case where $c(0) \leqslant b(0), \psi\left(n_{t+1}\right)$ is identically zero.

In economic terms, there are two reasons for the negative dependency of current research on future research, corresponding to the two places in which $n_{t+1}$ enters the expression for the marginal benefit of research, $b\left(n_{t+1}\right)$. That is, a foreseen increase in research next period discourages research this period (a) by raising future wages and hence reducing the flow of profits $\tilde{\pi}\left(\tilde{\omega}\left(N-n_{t+1}\right)\right)$ to be captured from the next innovation, and (b) by raising the rate of creative destruction $\lambda \varphi\left(n_{t+1}\right)$ next period and hence shortening the expected lifetime of the monopoly to be enjoyed by the next innovator.

A perfect foresight equilibrium (PFE) is defined as a sequence $\left\{n_{t}\right\}_{0}^{\infty}$ satisfying (3.2) for all $t \geqslant 0$. In Figure 1 the sequence $\left\{n_{0}, n_{1}, n_{2}, \ldots\right\}$ constructed from the

\footnotetext{
${ }^{7}$ The critical value $\bar{n}$ is defined by $c(0)=b(\bar{n})$, unless $\lim _{n \rightarrow N} b(n)>c(0)$, in which case $\bar{n}=N$.
} 
counterclockwise spiral starting at $n_{0}$ constitutes a PFE. A stationary equilibrium corresponds to a PFE with $n_{t}$ constant. It is defined as the solution to $\hat{n}=\psi(\hat{n})$.

There exists a unique stationary equilibrium. As Figure 1 shows, if $c(0)<b(0)$ then $\hat{n}$ is positive, and is defined by

$$
\frac{\tilde{\omega}(N-\hat{n})}{\lambda \varphi^{\prime}(\hat{n})}=\frac{\gamma \tilde{\pi}(\tilde{\omega}(N-\hat{n}))}{r+\lambda \varphi(\hat{n})} .
$$

In this case growth is positive because innovations arrive at the Poisson rate $\lambda \varphi(\hat{n})>0$. If $c(0) \geqslant b(0)$ then $\hat{n}=0$ and there is no growth, because the Poisson arrival rate of innovations is $\lambda \varphi(0)=0$. Henceforth, assume that $c(0)<b(0)$ and $\hat{n}>0$.

Other equilibria may also exist. A two-cycle is a pair $\left(n^{0}, n^{1}\right)$ such that $n^{0}=\psi\left(n^{1}\right)$ and $n^{1}=\psi\left(n^{0}\right)$. It defines a PFE of period two. If both $n^{0}$ and $n^{1}$ are positive, the PFE is a "real" two-cycle. If either $n^{0}$ or $n^{1}$ is zero, it is a "no-growth trap." In a real two-cycle, the prospect of high research in odd intervals discourages research in even intervals, and the prospect of low research in even intervals stimulates research in odd intervals. ${ }^{8}$ A no-growth trap is the extreme case in which the prospect of high research in odd intervals shuts down research completely in even intervals. Although the no-growth trap defines an infinite sequence $\left\{n_{t}\right\}_{0}^{\infty}$, the oscillation will cease after one innovation. From then on no growth will occur because no innovations will occur. It is clear from Figure 1 that a no-growth trap exists if $\lim _{\omega \rightarrow \infty} \tilde{\pi}(\omega)=0$ and $r$ is small enough. A real two-cycle will exist if a no-growth trap exists and ${ }^{9} c^{\prime}(\hat{n})+$ $b^{\prime}(\hat{n})>0$.

Consider the Cobb-Douglas example: $F(x)=x^{\alpha}$, with a linear research technology $\varphi(n) \equiv n$. From (2.8), the equation (3.3) defining a positive $\hat{n}$ is

$$
1=\frac{\lambda \gamma\left(\frac{1-\alpha}{\alpha}\right)(N-\hat{n})}{r+\lambda \hat{n}},
$$

\footnotetext{
${ }^{8}$ Shleifer (1986) also finds deterministic cycles in a model of multiple equilibria with innovations. The source of multiplicity in Shleifer's model is a contemporaneous strategic complementarity, whereby the incentive to innovate this period is stronger the more innovations are occurring elsewhere in the economy this period. No such strategic complementarity exists in the present model, in which more research this period raises the marginal cost of research without affecting the marginal benefit. Because Shleifer assumes that imitation destroys the return from innovations after one period, his model does not exhibit the dependency of current research upon future research which underlies the cycles, as well as the other equilibria, in the present model. Deneckere and Judd (1986) also generate cycles in a model of innovations. Their cycles arise from local instability of a unique equilibrium rather than from multiple equilibria. Like Shleifer, they also do not allow for any effect of future research upon current research.

${ }^{9}$ Consider the second-iterate function $\psi^{2}(n)$. Geometrically, $\psi^{2}$ is defined by reversing the spiral illustrated in Figure 1; thus $n_{0}=\psi^{2}\left(n_{2}\right)$. Suppose a no-growth trap exists. Then $0=\psi^{2}(n)<n$ for small but positive $n$ (see Figure 1). Because $c^{\prime}(\hat{n})+b^{\prime}(\hat{n})>0$, therefore the counterclockwise spiral in Figure 1 spirals out in the neighbourhood of $\hat{n}$, so that $\psi^{2}(n)>n$ for $n$ close to but less than $\hat{n}$. By the continuity of $\psi^{2}$ there must exist an $n^{0}$ strictly between 0 and $\hat{n}$ such that $\psi^{2}\left(n^{0}\right)=n^{0}$. Evidently $n^{0}, \psi\left(n^{0}\right)$ constitute a real two-cycle.
} 
and the condition for $\hat{n}$ to be positive is

$$
1<\lambda \gamma\left(\frac{1-\alpha}{\alpha}\right) N / r
$$

Since $\tilde{\pi}(\infty)=0$, a no-growth trap exists when $r$ is small. Since ${ }^{10} b^{\prime}(\hat{n}) / c^{\prime}(\hat{n}) \rightarrow 0$ uniformly in $r$ as $\alpha \rightarrow 0$, a real two-cycle exists when $\alpha$ and $r$ are small enough.

\section{B. Research in Stationary Equilibrium}

The rest of the paper focuses on stationary equilibria. Comparative-statics analysis of (3.3) shows the following proposition.

Proposition 1: The amount of research employment $\hat{n}$ in a stationary equilibrium increases with: $(a)$ a decrease in the rate of interest $r ;(b)$ an increase in the size $\gamma$ of each innovation; $(c)$ an increase in the total endowment $N$ of skilled labor; or $(d)$ an increase in the arrival parameter $\lambda$.

This proposition is intuitive: (a) A decrease in the rate of interest increases the marginal benefit to research, by raising the present value of monopoly profits. (b) An increase in the size of each innovation also increases the marginal benefit to research, by raising the size of next interval's monopoly profits relative to this interval's productivity. (c) An increase in the endowment of skilled labor both increases the marginal benefit and reduces the marginal cost of research, by reducing the wage of skilled labor. (d) An increase in the

${ }^{10}$ In this example

$$
b(n) \equiv \frac{\gamma \tilde{\pi}(\tilde{\omega}(N-n))}{r+\lambda n} \quad \text { and } \quad c(n) \equiv \tilde{\omega}(N-n) / \lambda .
$$

Therefore

$$
b^{\prime}(n)=\frac{-\gamma \tilde{\pi}^{\prime}(\tilde{\omega}(N-n)) \tilde{\omega}^{\prime}(N-n)-\lambda b(n)}{r+\lambda n} \quad \text { and } \quad c^{\prime}(n)=-\tilde{\omega}^{\prime}(N-n) / \lambda .
$$

Because $\lambda b(\hat{n})=\lambda c(\hat{n})=\tilde{\omega}(N-\hat{n})$, therefore

$$
b^{\prime}(\hat{n}) / c^{\prime}(\hat{n})=\frac{\lambda \gamma \tilde{\pi}^{\prime}(\tilde{\omega}(N-\hat{n}))+\lambda \tilde{\omega}(N-\hat{n}) / \tilde{\omega}^{\prime}(N-\hat{n})}{r+\lambda \hat{n}} .
$$

But $\tilde{\pi}^{\prime}(\tilde{\omega}(N-\hat{n}))=-(N-\hat{n})$ and $\tilde{\omega}(N-\hat{n})=\alpha^{2}(N-\hat{n})^{\alpha-1}$. Therefore

$$
b^{\prime}(\hat{n}) / c^{\prime}(\hat{n})=-\frac{\lambda(N-\hat{n})}{r+\lambda \hat{n}}\left(\gamma+\frac{1}{1-\alpha}\right)
$$

From this and (3.4),

$$
b^{\prime}(\hat{n}) / c^{\prime}(\hat{n})=-\left(\frac{\alpha}{\gamma(1-\alpha)}\right)\left(\gamma+\frac{1}{1-\alpha}\right) \rightarrow 0 \text { uniformly in } r \text { as } \alpha \rightarrow 0 .
$$


arrival parameter decreases both the marginal cost and the marginal benefit of research, because on the one hand it results in more "effective" units of research for any given level of employment, but on the other hand it also increases the rate of creative destruction during the next interval. The former effect dominates.

The above discussion of result (d) suggests an interesting implication of creative destruction that could arise if the arrival parameter $\lambda$ were permitted to vary from one interval to the next. Suppose, for example, that with each successful innovation a new value of $\lambda$ was drawn from the finite set $\left\{\lambda_{1}, \ldots, \lambda_{m}\right\}$ according to a fixed transition matrix $B$. Transition into a high- $\lambda$ state could represent a fundamental breakthrough leading to a Schumpeterian wave of innovations, whereas transition to a low- $\lambda$ state could represent the exhaustion of a line of research. Then a stationary equilibrium would involve not one level of research employment but one for each state. Now consider the effects of a ceteris paribus increase in $\lambda_{2}$. This parameter change might raise research employment in state 2 , but it would tend to reduce research employment in other states, by increasing the rationally expected rate of creative destruction during the next interval. Furthermore, even though the parameter change represents an unambiguous improvement in the productivity of the research technology, it might reduce the average level of research employment in stationary equilibrium. Indeed, Appendix 1 works out a numerical example in which, in the limit, as $\lambda_{2}$ becomes infinite, average research employment falls to zero.

The linear Cobb-Douglas example of (3.4) and (3.5) above yields an additional comparative-statics result by parameterizing the degree of market power enjoyed by an intermediate monopolist. Specifically, $1-\alpha$ is the Lerner (1934) measure of monopoly power (price minus marginal cost divided by price), $(1-\alpha)^{-1}$ is the elasticity of demand faced by an intermediate monopolist, and $1-\alpha$ is the fraction of equilibrium revenue in the intermediate sector accruing to the monopolist, $\pi_{t} /\left(\pi_{t}+w_{t} x_{t}\right)$. Thus, by all measures, the degree of market power is measured inversely by the parameter $\alpha$.

According to (3.4), an increase in the degree of market power (decrease in $\alpha$ ) increases the stationary-equilibrium amount of research $\hat{n}$ whenever $\hat{n}$ is positive. According to (3.5), given fixed values of the parameters $\gamma, \lambda, r$, and $N$, the stationary-equilibrium amount of research will be positive if and only if there is at least some minimal degree of market power; that is, if and only if $\alpha$ is less than the critical value

$$
\alpha^{*} \equiv \frac{\lambda \gamma N}{\lambda \gamma N+1}<1
$$

If the degree of market power falls short of this minimal value, then the flow of monopoly profits from the next innovation would not be enough to induce positive research aimed at capturing those rents even if they could be retained forever, with no creative destruction in the next interval. 


\section{C. Balanced Growth}

Real output (i.e. the flow of consumption goods) in the economy during interval $t$ is

$$
y_{t}=A_{t} F(N-\hat{n}),
$$

which implies

$$
y_{t+1}=\gamma y_{t} .
$$

Thus the time path of the $\log$ of real output $\ln y(\tau)$ will be a random step-function starting at $\ln y_{0}=\ln F(N-\hat{n})+\ln A_{0}$, with the size of each step equal to the constant $\ln \gamma>0$, and with the time between each step $\left\{\Delta_{1}, \Delta_{2}, \ldots\right\}$ a sequence of iid variables exponentially distributed with parameter $\lambda \varphi(\hat{n})$. This statement and (3.3) fully specify the stochastic process driving output, in terms of the parameters of the model.

Not surprisingly, this stochastic process is nonstationary. Suppose observations were made at discrete points in time 1 unit apart. Then from (3.7),

$$
\ln y(\tau+1)=\ln y(\tau)+\varepsilon(\tau)
$$$$
(\tau=0,1, \ldots)
$$

where $\varepsilon(\tau)$ is $\ln \gamma$ times the number of innovations between $\tau$ and $\tau+1$. From the above analysis

$$
\left\{\frac{\varepsilon(0)}{\ln \gamma}, \frac{\varepsilon(1)}{\ln \gamma}, \ldots\right\}
$$

is a sequence of iid variables distributed Poisson with parameter $\lambda \varphi(\hat{n})$. Thus (3.8) can be written as

$$
\ln y(\tau+1)=\ln y(\tau)+\lambda \varphi(\hat{n}) \ln \gamma+e(\tau)
$$$$
(\tau=0,1, \ldots) \text {, }
$$

where $e(\tau) \equiv \varepsilon(\tau)-\lambda \varphi(\hat{n}) \ln \gamma$. Note that $e(\tau)$ is iid., with

$$
E(e(\tau))=0, \quad \operatorname{var} e(\tau)=\lambda \varphi(\hat{n})(\ln \gamma)^{2} .
$$

From (3.9) and (3.10), the discrete sequence of observations on the log of output follows a random walk with constant positive drift. It also follows that the economy's average growth rate $(A G R)$ and the variance of the economy's growth rate $(V G R)$ are given by

$$
A G R=\lambda \varphi(\hat{n}) \ln \gamma, \quad V G R=\lambda \varphi(\hat{n})(\ln \gamma)^{2} .
$$

Combining (3.11) with Proposition 1 allows one to sign the impact of parameter changes on the average growth rate. Increases in the arrival parameter, the size of innovations, the size of skilled labor endowment, and (in the CobbDouglas example) the degree of market power all raise $A G R$. Increases in the rate of interest lower it. The parameter changes have the same qualitative effect on $V G R$ as on $A G R$. The effects are intuitive and straightforward. The effect of market power, combined with the finding that a minimal degree of market power is needed before growth is even possible, underlines the importance of imperfect competition for the growth process. 
The example of Appendix 1 shows, however, that in a more general setting where the arrival parameter $\lambda$ can vary from state to state, it is not always true that an unambiguous improvement in the productivity of the research technology will increase the economy's average growth rate. Instead, an increase in the arrival parameter in one state can discourage research in other states by increasing the rationally expected rate of creative destruction to such an extent that the economy's average growth rate falls.

\section{WELFARE PROPERTIES OF THE STATIONARY EQUILIBRIUM}

This section compares the laissez-faire average growth rate derived above with the $A G R$ that would be chosen by a social planner whose objective was to maximize the expected present value of consumption $y(\tau)$. Since every innovation raises $y(\tau)$ by the same factor $\gamma$, the optimal policy consists of a fixed level of research. Expected welfare is

$$
U=\int_{0}^{\infty} e^{-r \tau} \sum_{t=0}^{\infty} \Pi(t, \tau) A_{t} F(N-n) d \tau,
$$

where $\Pi(t, \tau)$ equals the probability that there will be exactly $t$ innovations up to time $\tau$. Given that the innovation process is Poisson with parameter $\lambda \varphi(n)$, we have

$$
\Pi(t, \tau)=(\lambda \varphi(n) \tau)^{t} e^{-\lambda \varphi(n) \tau} / t !
$$

From (4.1) and (4.2),

$$
U=\frac{A_{0} F(N-n)}{r-\lambda \varphi(n)(\gamma-1)} .
$$

Equation (4.3) identifies $U$ as the initial flow of output $A_{0} F(x)$ discounted at the rate $r-\lambda \varphi(n)(\gamma-1)$. This "social discount rate" is less than the rate of interest $r$ because the stream of output will be growing over time. More specifically, the social discount rate is the rate at which each risk-neutral individual in the economy would capitalize a stream that was perpetually subject to increases by the factor $(\gamma-1)$ with a Poisson arrival rate of $\lambda \varphi(n)$, and constant otherwise.

The socially optimal level of research $n^{*}$ maximizes $U$. The first-order condition for an interior maximum is

$$
\frac{F^{\prime}\left(N-n^{*}\right)}{\lambda \varphi^{\prime}\left(n^{*}\right)}=\frac{(\gamma-1) F\left(N-n^{*}\right)}{r-\lambda \varphi\left(n^{*}\right)(\gamma-1)} .
$$

(If no solution exists to (4.4) then $n^{*}=0$.) This level of research would produce an average growth rate of $\lambda \varphi\left(n^{*}\right) \ln \gamma$. Accordingly laissez-faire produces an average growth rate more (less) than optimal if $\hat{n}>(<) n^{*}$. Which way these inequalities go can be checked by comparing (4.4) with the equation determin- 
ing the stationary equilibrium level of research $\hat{n}$ :

$$
\frac{\tilde{\omega}(N-\hat{n})}{\lambda \varphi^{\prime}(\hat{n})}=\frac{\gamma \tilde{\pi}(\tilde{\omega}(N-\hat{n}))}{r+\lambda \varphi(\hat{n})} .
$$

There are four differences between (4.4) and (3.3). The first is that the social discount rate $r-\lambda \varphi(n)(\gamma-1)$ appears in (4.4) instead of the "private discount rate" $r+\lambda \varphi(n)$. The social rate is less than the rate of interest, whereas the private rate is greater. This difference corresponds to the intertemporal spillover effect discussed in Section 2. The social planner takes into account that the benefit to the next innovation will continue forever, whereas the private research firm attaches no weight to the benefits that accrue beyond the succeeding innovation. ${ }^{11}$

The second difference is that total output $F\left(N-n^{*}\right)$ appears on the righthand side of (4.4) instead of the flow of profits $\tilde{\pi}(\tilde{\omega}(N-\hat{n}))$ that appears in the marginal benefit in (3.3). This is the "appropriability" effect familiar from the patent-race literature.

The third difference is that the factor $(\gamma-1)$ in (4.4) replaces $\gamma$ in the marginal benefit of (3.3). This corresponds to a "business-stealing" effect. The private research firm does not internalize the loss to the previous monopolist caused by an innovation. In contrast, the social planner takes into account that an innovation destroys the social return from the previous innovation. ${ }^{12}$

The fourth difference is that the marginal product $F^{\prime}\left(N-n^{*}\right)$ appears in (4.4) in place of the wage $\tilde{\omega}(N-\hat{n})$ in the marginal cost in (3.3). This is a "monopoly-distortion" effect which does not appear in the partial-equilibrium patent-race literature. Specifically, the social cost of research employment exceeds the private cost because in laissez-faire the alternative user of skilled research labor is a monopolist.

\footnotetext{
${ }^{11}$ Two additional spillovers could easily be included. First, researchers could benefit from the flow of others' research, so that an individual firm's arrival rate would be a constant-returns function of its own and others' research. Second, there could be an exogenous Poisson arrival rate $\mu$ of imitations that costlessly circumvent the patent laws and clone the existing intermediate good. Both would have the effect of lowering AGR. Also, as shown in Aghion and Howitt (1988), the inclusion of $\mu$ would introduce another source of cycles in the economy, since each imitation would make the intermediate industry perfectly competitive, which would raise manufacturing employment, until the next innovation arrives.

${ }^{12}$ In the patent-race literature the business-stealing effect is usually derived in a symmetric model with no incumbent, in which all research firms enjoy some positive surplus because there is no free entry. An example is Mortensen (1982), who identifies the business-stealing effect with the comment: "Wasteful competition arises because none of the contestants takes account of the loss of the prospect that others suffer when the former's discovery ends the game" (p. 970). In the present paper the loss accrues not to the other research firms, whose value remains equal to zero, by free entry, even after an innovation by another firm, but to the incumbent monopolist who, because of the replacement effect, has chosen not to participate in the patent race. As Tirole $(1988$, p. 399) notes, there is another negative externality that would occur if the research technology had memory. Specifically, a firm might engage in research in order to reduce the probability that its rivals will win the race. This effect is absent from the present model, in which one firm's research has no effect on the others' probabilities of innovating.
} 
The intertemporal-spillover and appropriability effects tend to make the laissez-faire average growth rate less than optimal, whereas the business-stealing and monopoly-distortion effects tend to make it greater than optimal. Because these effects conflict with each other, the laissez-faire average growth rate may be more or less than optimal. This can be seen in the linear Cobb-Douglas example, where $n^{*}$ and $\hat{n}$ satisfy

$$
\begin{aligned}
& 1=\frac{\lambda(\gamma-1)\left(\frac{1}{\alpha}\right)\left(N-n^{*}\right)}{r-\lambda n^{*}(\gamma-1)}, \\
& 1=\frac{\lambda \gamma\left(\frac{1-\alpha}{\alpha}\right)(N-\hat{n})}{r+\lambda \hat{n}} .
\end{aligned}
$$

In this example, the appropriability and monopoly-distortion effects are combined in the presence of the factor $(1-\alpha)$ in (3.4); together they tend to make the laissez-faire AGR less than optimal. This combined effect together with the intertemporal-spillover effect dominates when the size of innovations $\gamma$ is large, in which case ${ }^{13} \hat{n}<n^{*}$. However, when there is much monopoly power ( $\alpha$ close to zero) and innovations are not too large, the business-stealing effect dominates, in which case ${ }^{14} \hat{n}>n^{*}$.

\section{NONDRASTIC INNOVATIONS}

Until this point the analysis has assumed that innovations are drastic; that the intermediate monopolist is not constrained by potential competition from owners of previous patents. The present section shows that the analysis of stationary equilibria can be generalized to the case where innovations are nondrastic.

Innovations are nondrastic if and only if the previous incumbent could make a positive profit when the current one was charging the price $p_{t}=A_{t} F^{\prime}\left(\tilde{x}\left(\omega_{t}\right)\right)$ which yields an unconstrained maximum to the current incumbent's profit. If innovations are nondrastic, the current incumbent sets the maximum price that gives the previous incumbent nonpositive profits, and satisfies all the demand at that price, leaving none to the previous incumbent.

The previous incumbent could make a positive profit if and only if a competitive producer of consumption goods could produce at an average cost of less than unity by combining unskilled labor with the previous incumbent's good, buying the latter at a price equal to its average cost of production $w_{t}$; that

\footnotetext{
${ }^{13}$ From (4.5), as $\gamma$ rises to the upper limit $1+r / \lambda N, n^{*}$ approaches $N$ while, from (3.4), $\hat{n}$ is bounded below $N$.

${ }^{14}$ If $1 / \alpha>1+r / \lambda N$, then $\hat{n}>0$ for all $\gamma$, whereas if $\gamma \leqslant 1+\alpha r / \lambda N$, then $n^{*}=0$. These inequalities are compatible with the condition derived below for innovations to be drastic, namely that $\gamma \geqslant \alpha^{-\alpha}$, as can be verified with the example: $\alpha=1 / 2, \gamma=\sqrt{2}, r / \lambda N=2(\sqrt{2}-1)$.
} 
is, if and only if the condition

$$
C\left(w_{t}^{M}, w_{t}\right) \leqslant A_{t-1}
$$

were to hold with strict inequality, where $w_{t}^{M}$ is the equilibrium wage of unskilled labor and $C$ is the unit-cost function associated with the production function $F$.

In equilibrium all the unskilled labor is combined with the current incumbent's intermediate good. Thus the unskilled wage must satisfy the competitive equilibrium condition:

$$
C\left(w_{t}^{M}, p_{t}\right)=A_{t} .
$$

It follows that innovations are nondrastic if and only if (5.1) holds with strict inequality when $w_{t}^{M}$ satisfies (5.2) together with $p_{t}=A_{t} F^{\prime}\left(\tilde{x}\left(\omega_{t}\right)\right)$. It also follows that if innovations are nondrastic then $p_{t}$ and $w_{t}^{M}$ satisfy (5.2) and (5.1) with equality.

In the Cobb-Douglas example, where the unconstrained optimal price for the current incumbent is $w_{t} / \alpha$, innovations are nondrastic if and only if

$$
\gamma<\alpha^{-\alpha}
$$

in which case ${ }^{15}$

$$
p_{t}=\gamma^{1 / \alpha} w_{t}, \quad \pi_{t}=\left(\gamma^{1 / \alpha}-1\right) w_{t} x_{t}, \quad x_{t}=\left(\gamma^{1 / \alpha} \omega_{t} / \alpha\right)^{1 /(\alpha-1)} .
$$

The rest of the analysis of this section will focus on stationary equilibria with positive growth in the linear Cobb-Douglas example.

The analysis assumes that the monopolist chooses to do no research, as in the case of drastic innovations. This implicitly places a lower bound on the size of innovations, because it requires the efficiency effect to be smaller than the replacement effect. Appendix 2 shows that the condition

$$
\gamma^{1 / \alpha}\left(1+\gamma^{-1}\right) \geqslant \gamma^{-1}+\min \left\{\gamma^{2 / \alpha}, \alpha^{-1}\right\}
$$

is sufficient for the monopolist to do no research. Note that this condition is satisfied when $\gamma$ is close to the value $\alpha^{-\alpha}$ at which innovations become drastic.

If there is positive research during interval $t$, then, as before,

$$
\frac{w_{t}}{\lambda \varphi^{\prime}\left(n_{t}\right)}=\frac{\pi_{t+1}}{r+\lambda \varphi\left(n_{t+1}\right)} .
$$

${ }^{15}$ In the Cobb-Douglas example, the unit-cost function is

$$
c\left(w^{M}, p\right) \equiv(1-\alpha)^{-(1-\alpha)} \alpha^{-\alpha} p^{\alpha}\left(w^{M}\right)^{1-\alpha} .
$$

It follows from this and (5.2) that if the incumbent charged the unconstrained profit-maximizing price $\alpha^{-1} w_{t}$, the unskilled wage would be $w_{t}^{M}=(1-\alpha) \alpha^{2 \alpha /(1-\alpha)} A_{t}\left(w_{t} / A_{t}\right)^{-\alpha /(1-\alpha)}$. Putting this into (5.1) yields the condition $\gamma \leqslant \alpha^{-\alpha}$. Treating (5.1) as an equality and solving it and (5.2) simultaneously for $\left(w_{t}^{M}, p_{t}\right)$ yields $p_{t}=\gamma^{\mathrm{i} / \alpha} w_{t}$. 
In a stationary equilibrium with positive growth, (5.4) and (5.6) imply

$$
1=\frac{\lambda \gamma\left(\gamma^{1 / \alpha}-1\right)(N-\hat{n})}{r+\lambda \hat{n}} .
$$

Equation (5.7) defines the stationary equilibrium level of research $\hat{n}$. It is the same as the equation (3.4) that applies in the drastic case, except that the markup $\gamma^{1 / \alpha}$ in (5.7) replaces the markup $\alpha^{-1}$ in (3.4). The comparative-statics results of Proposition 1 apply to the solution of (5.7). In addition, the stationary equilibrium level of research defined by (5.7) is increased by an increase in market power (a decrease in $\alpha$ ) as in the drastic case. Thus in the linear Cobb-Douglas example all the comparative statics results derived for the case of drastic innovations are valid also when innovations are nondrastic.

Comparison of (5.7) and (4.5) shows that the same welfare effects analyzed in Section 4 operate in the case where innovations are nondrastic, again with the result that research and growth under laissez-faire may be more or less than optimal. ${ }^{16}$

As is customary in the patent-race literature this analysis has ruled out the possibility that the current and previous incumbent might contract to share the higher monopoly profits that could be earned if the previous incumbent agreed never to compete. For example, the previous incumbent might sell its patent to the current one; in the extreme case where the previous incumbent always had no bargaining power in negotiation with the current one, competition from previous vintages of the intermediate good would never constrain the monopolist, and the above analysis of drastic innovations would apply no matter how small the innovations were.

\section{ENDOGENOUS SIZE OF INNOVATIONS}

This section generalizes the analysis of stationary equilibria by allowing research firms to choose not only the frequency but also the size of innovations. It shows that under laissez-faire, innovations will be too small if they are drastic. In the nondrastic case, the tendency to make innovations too small is at least partly mitigated by the incentive for innovators to move away from their competitive fringe, which they can do by increasing the size of innovations.

Assume that the arrival rate of innovations to a firm employing the factor combination $(z, s)$ and aiming for innovations of size $\gamma$ is $\lambda \phi(z, s) v(\gamma)$, where $v^{\prime}(\gamma)<0$; the bigger the innovation, the harder it is to discover. Assume $v^{\prime \prime}(\gamma)<0$; the marginal cost (in terms of lower arrival rate) of aiming for larger innovations increases with the size of innovations. Then the product $\gamma v(\gamma)$ is a concave function of $\gamma$.

\footnotetext{
${ }^{16}$ Suppose $\gamma=\sqrt{2}$ and $\alpha=1 / 2$. To get $\hat{n}<n^{*}$ let $r$ approach $(\sqrt{2}-1) \lambda N$ from above; then $n^{*}$ approaches $N$ whereas $\hat{n}$ is bounded below $N$. To get $\hat{n}>n^{*}$ let $r=2(\sqrt{2}-1) \lambda N$; then $n^{*}=0$ and $\hat{n}>0$. In either case $\gamma=\alpha^{-\alpha}$, but the example is robust to a small decrease in $\gamma$ that would satisfy the necessary and sufficient condition (5.3) for innovations to be nondrastic without violating the sufficient condition (5.5) for the monopolist to do no research.
} 
The analysis focuses again on stationary equilibria with positive growth. Consider first the case of drastic innovations. By the same logic as before, the payoff to the $t+1$ st innovator is

$$
V_{t+1}=\frac{A_{t+1} \tilde{\pi}(\hat{\omega})}{r+\lambda \varphi(\hat{n}) v(\hat{\gamma})},
$$

where $\hat{\gamma}$ is the stationary-equilibrium value of $\gamma$. If the $t+1$ st innovation has size $\gamma$, not necessarily equal to $\hat{\gamma}$, then $A_{t+1}=\gamma A_{t}$ and $V_{t+1}=\gamma V_{t}$. Therefore the expected flow of profits to the research firm in interval $t$ is

$$
\lambda \phi(z, s) v(\gamma) \gamma V_{t}-w_{t} z-w_{t}^{s} s
$$

The firm takes $V_{t}$ as given. Thus its profit-maximizing choice of $\gamma$ also maximizes the product $v(\gamma) \gamma$. Because this product is a concave function of $\gamma$, therefore $\hat{\gamma}$ is defined by the condition ${ }^{17}$

$$
v(\hat{\gamma})+\hat{\gamma} v^{\prime}(\hat{\gamma})=0 .
$$

The first-order condition for profit maximization with respect to skilled labor, together with (6.1) produces an expression analogous to (3.3):

$$
\frac{\tilde{\omega}(N-\hat{n})}{\lambda \varphi^{\prime}(\hat{n})}=\frac{v(\hat{\gamma}) \hat{\gamma} \tilde{\pi}(\tilde{\omega}(N-\hat{n}))}{r+\lambda \varphi(\hat{n}) v(\hat{\gamma})} .
$$

The comparative statics analysis of Section 3 carries through unchanged, since $\hat{\gamma}$ is determined by (6.3) independently of all parameters that do not enter the function $v$, with the obvious exception that it is no longer permissible to investigate the effects of a change in $\gamma$.

As in Section 4, the expected present value of consumption equals

$$
U=\frac{A_{0} F(N-n)}{r-\lambda \varphi(n) v(\gamma)(\gamma-1)},
$$

where the denominator is the social discount rate. Therefore, independently of the choice of $n$, the social planner will choose $\gamma$ so as to maximize the expression $v(\gamma)(\gamma-1)$. The socially optimal value $\gamma^{*}$ is then defined by

$$
v\left(\gamma^{*}\right)+\gamma^{*} v^{\prime}\left(\gamma^{*}\right)-v^{\prime}\left(\gamma^{*}\right)=0 .
$$

By concavity of $\gamma v(\gamma),{ }^{18} \hat{\gamma}<\gamma^{*}$. Innovations are too small under laissez-faire. This result is another manifestation of the business-stealing effect. The social planner chooses $\gamma$ so as to maximize the arrival rate multiplied by the net size $(\gamma-1)$ of innovations, whereas the private research firm, which does not internalize the loss of the existing vintage of intermediate good, maximizes the arrival rate times the gross size $\gamma$.

\footnotetext{
${ }^{17}$ Note that it is always possible to choose the function $v$ so that the solution to (6.3) satisfies the condition for innovations to be drastic in the Cobb-Douglas example: $\gamma \geqslant \alpha^{-\alpha}$.

${ }^{18}$ Since $v^{\prime}<0,(6.6)$ implies that $v(\gamma) \gamma$ is locally decreasing at $\gamma^{*}$, so that $\gamma^{*}$ exceeds the point $\hat{\gamma}$ at which $v(\gamma) \gamma$ is maximized.
} 
The socially optimal level of research employment $n^{*}$ satisfies the condition

$$
\frac{F^{\prime}\left(N-n^{*}\right)}{\lambda \varphi^{\prime}\left(n^{*}\right)}=\frac{v\left(\gamma^{*}\right)\left(\gamma^{*}-1\right) F\left(N-n^{*}\right)}{r-\lambda \varphi\left(n^{*}\right) v\left(\gamma^{*}\right)\left(\gamma^{*}-1\right)} .
$$

Comparison between (6.4) and (6.7) reveals the same welfare effects as in the analysis of Section 4. In addition, the fact that $\hat{\gamma}<\gamma^{*}$ in itself makes $\hat{n}<n^{*}$. This is because, as we have seen, $v(\hat{\gamma})(\hat{\gamma}-1)<v\left(\gamma^{*}\right)\left(\gamma^{*}-1\right)$. So if the other four effects were absent, and both $\hat{n}$ and $n^{*}$ were determined by (6.7), the effect on research employment would be the same as if the laissez-faire economy had a smaller arrival parameter $\lambda$, which would reduce $\hat{n}$ below $n^{*}$.

The economy's average growth rate $\lambda \varphi(\hat{n}) \nu(\hat{\gamma}) \ln \hat{\gamma}$ is affected by the fact that innovations are too small under laissez-faire, although the direction of the overall effect is ambiguous. The direct effect on $\ln \hat{\gamma}$ is to decrease $A G R$. The direct effect on the arrival rate $\lambda \varphi(\hat{n}) v(\hat{\gamma})$ is to increase $A G R$. The indirect effect on the arrival rate working through $\varphi(\hat{n})$ is to decrease $A G R$.

In the nondrastic case, the above business-stealing effect whereby innovations are too small under laissez-faire is mitigated by an additional effect, namely that private innovators tend to increase the size of innovations in order to increase their profit margins. This margin is independent of the size $\gamma$ in the drastic case but it increases with $\gamma$ in the nondrastic case. (In the Cobb Douglas example the profit margin is $\alpha^{-1}-1$ if the innovation is drastic and $\gamma^{1 / \alpha}-1$ if nondrastic.) The following example shows, however, that this additional "profit-margin" effect does not necessarily overturn our earlier result to the effect that innovations are too small.

EXAMPLE: Let $\varphi(n)=n, F(x)=x^{1 / 2}$. From (5.3) innovations are nondrastic if $\gamma<\sqrt{2}$. From (5.4), the payoff to the $(t+1)$ st innovator in a stationary equilibrium is

$$
V_{t+1}=\frac{\left(\gamma^{2}-1\right) x(\hat{\omega}, \gamma) w_{t+1}}{r+\lambda v(\hat{\gamma})(N-x(\hat{\omega}, \gamma))},
$$

where $x(\hat{\omega}, \gamma)=\left(2 \hat{\omega} \gamma^{2}\right)^{-2}$. In (6.8), $\gamma$ is the size of innovation to be chosen by the innovator during interval $t$, whereas $\hat{\gamma}$ and $\hat{\omega}$ denote stationary-equilibrium values which the innovator takes as given. As in the drastic case, $w_{t+1}=\gamma w_{t}$. Therefore $\hat{\gamma}$ must solve the equation

$$
\hat{\gamma}=\underset{\{\gamma\}}{\arg \max } \frac{v(\gamma)\left(\gamma^{2}-1\right) x(\hat{\omega}, \gamma) \gamma w_{t}}{r+\lambda v(\hat{\gamma})(N-x(\hat{\boldsymbol{\omega}}, \gamma))} .
$$

Since $\partial x / \partial \gamma<0$, we have

$$
\hat{\gamma}<\operatorname{argmax} v(\gamma)\left(\gamma^{2}-1\right) x(\hat{\omega}, \gamma) \gamma=\bar{\gamma} .
$$

From the above analysis we know that

$$
\operatorname{argmax} v(\gamma)(\gamma-1)=\gamma^{*} \text {. }
$$


Therefore a sufficient condition for $\hat{\gamma}<\gamma^{*}$ is that $\left(\gamma^{2}-1\right) x(\hat{\omega}, \gamma) \gamma=$ $(\gamma-1) g(\gamma)$ with $g^{\prime}(\gamma)<0$. The latter is true, ${ }^{19}$ with $g(\gamma) \equiv(\gamma+1) \gamma / 4 \hat{\omega}^{2} \gamma^{4}$.

\section{STRATEGIC MONOPSONY EFFECT}

In this section the intermediate firm is assumed to take into account its influence on the amount of current research and thereby on the probability of its replacement. In particular, by increasing its demand $x_{t}$ for skilled labor, the monopolist can raise the wage rate that must also be paid to skilled workers in research. The effect is to reduce the equilibrium amount of research $n_{t}$ and consequently to delay the arrival of the $(t+1)$ st innovation. The monopolist will trade this gain off against the higher wages it must pay its own skilled labor.

The analysis focuses on stationary equilibria with positive growth. The monopolist during interval $t$ chooses $x_{t}$ to maximize the expected present value of profits:

$$
V_{t}=\frac{\left(A_{t} F^{\prime}(x)-w_{t}\right) x}{r+\lambda \varphi(N-x)}
$$

subject to

$$
w_{t}=\lambda \varphi^{\prime}(N-x) V_{t+1},
$$

where $(*)$ follows from (2.10). The magnitudes $x_{t}, n_{t}, V_{t} / A_{t}$, and $w_{t} / A_{t}$ are constant, at the equilibrium values $\bar{x}, \bar{n}, \bar{V}$, and $\bar{\omega}$. Therefore $\bar{x}$ solves

$$
\bar{V}=\max _{x} \frac{\left[F^{\prime}(x)-\lambda \gamma \varphi^{\prime}(N-x) \bar{V}\right] x}{r+\lambda \varphi(N-x)} .
$$

The first-order condition is

$$
F^{\prime}(\bar{x})+\bar{x} F^{\prime \prime}(\bar{x})=\lambda \bar{V}\left[(\gamma-1) \varphi^{\prime}(N-\bar{x})-\bar{x} \gamma \varphi^{\prime \prime}(N-\bar{x})\right] .
$$

From the constraint $\left({ }^{*}\right)$,

$$
\bar{\omega}=\lambda \gamma \varphi^{\prime}(N-\bar{x}) \bar{V} .
$$

From (7.2), (7.3), and the definition of $\tilde{\omega}$,

$$
\bar{\omega}=\left[\frac{\gamma}{\gamma-1-\gamma(N-\bar{n}) \varphi^{\prime \prime}(\bar{n}) / \varphi^{\prime}(\bar{n})}\right] \tilde{\omega}(N-\bar{n}) \equiv \bar{\omega}(\bar{n}) .
$$

It follows that the stationary-equilibrium level of research $\bar{n}$ is given by the analogue to (3.3):

$$
\left[\frac{\tilde{\omega}(N-\bar{n})}{\lambda \varphi^{\prime}(\bar{n})}\right]\left[\frac{\gamma}{\gamma-1-\gamma(N-\bar{n}) \varphi^{\prime \prime}(\bar{n}) / \varphi^{\prime}(\bar{n})}\right]=\frac{\gamma \bar{\pi}(\bar{n})}{r+\lambda \varphi(\bar{n})},
$$

\footnotetext{
${ }^{19}$ Because it compares $\gamma^{*}$ with $\bar{\gamma}$, this analysis would apply even if the research firm ignored the regative effect that its choice of $\gamma$ has on the value of an innovation by reducing the equilibrium evel of $x_{t+1}$ and hence raising the rate of creative destruction next period.
} 
where the function $\bar{\pi}$ is defined as

$$
\bar{\pi}(\bar{n}) \equiv\left[F^{\prime}(N-\bar{n})-\bar{\omega}(\bar{n})\right](N-\bar{n}) .
$$

Assume that the expression $(N-n) \varphi^{\prime \prime}(n)$ is nondecreasing in $n$. Then the left-hand side of (7.5) is increasing in $\bar{n}$. If the right-hand side is still decreasing, then the solution to (7.5) is unique. It is straightforward to verify that all the comparative statics results in Proposition 1 apply to this solution, and that in the Cobb-Douglas example the solution is an increasing function of the degree of market power.

Welfare analysis of stationary equilibria is somewhat affected by the strategic monopsony effect, but the overall result remains, namely that the laissez-faire average growth rate may be more or less than optimal. Comparison of (7.5) with (4.4) reveals the same intertemporal-spillover, appropriability, business-stealing, and monopoly-distortion effects as before, although the monopoly-distortion effect will be quantitatively different because $\bar{\pi}(n) \not \equiv \tilde{\pi}(\tilde{\omega}(N-n))$. There is an additional effect, however, from the presence of the term

$$
\left[\frac{\gamma}{\gamma-1-\gamma(N-\bar{n}) \varphi^{\prime \prime}(\bar{n}) / \varphi^{\prime}(\bar{n})}\right]
$$

on the left-hand side of (7.5). This additional effect is the "monopsony-distortion" effect.

In the linear case, where $\varphi^{\prime \prime}$ is zero, the constraint $\left(^{*}\right)$ indicates that the intermediate firm's wage rate is independent of the amount of skilled labor it hires, so the monopsony-distortion effect induces it to hire more skilled workers in order to reduce the amount of current research, and hence the amount of creative destruction. The effect just cancels the business-stealing effect, as can be seen by multiplying both sides of (7.5) by $(\gamma-1) / \gamma$. Thus in the linear Cobb-Douglas example, research and growth are unambiguously less than optimal.

In the general case where $\varphi^{\prime \prime}<\theta$ the monopsony-distortion effect is ambiguous, because hiring more skilled labor increases the intermediate firm's wage rate at the same time that it reduces creative destruction. Because of these conflicting tendencies it is straightforward to construct examples in which the overall monopsony-distortion effect vanishes. More specifically, given any specification of the model it is possible to perturb the research function $\varphi$ in such a way ${ }^{20}$ that $\hat{n}$ and $n^{*}$ remain unchanged and the solution $\bar{n}$ to (7.5) becomes equal to $\hat{n}$. Since $\hat{n}$ can be more or less than $n^{*}$ it follows that $\bar{n}$ can be more or less than $n^{*}$.

The rest of the paper ignores the strategic monopsony effect, by assuming that intermediate firms take as given the wage of skilled labor and the amount

${ }^{20}$ Just perturb $\varphi$ in such a way that $\varphi(\hat{n}), \varphi\left(n^{*}\right), \varphi^{\prime}(\hat{n})$, and $\varphi^{\prime}\left(n^{*}\right)$ remain unchanged, but $\varphi^{\prime \prime}(\hat{n})$ is made equal to $-\varphi^{\prime}(\hat{n}) / \gamma(N-\hat{n})$. This can be done without altering the sign of $\varphi^{\prime}$ and $\varphi^{\prime \prime}$ on $[0, N)$. According to (3.3) and (4.4), $\hat{n}$ and $n^{*}$ will be unchanged. This perturbation makes the second factor on the left-hand side of (7.5) equal to unity when $\bar{n}=\hat{n}$, and makes $\bar{\pi}(\hat{n})=\tilde{\pi}(\tilde{\omega}(N-$ $\hat{n})$ ). Since $\hat{n}$ solves (3.3) it will now also solve (7.5). 
of research. This assumption is based on our belief that the effect is not important, because it derives from the simplifying assumption that there is only one intermediate firm in the economy. If there were many competing intermediate firms, as in the next section, each might plausibly regard itself as too small to affect the skilled wage or the amount of research.

\section{MANY INTERMEDIATE GOODS}

This section relaxes the simplifying assumption of a single economy-wide monopoly in intermediate goods. Suppose instead that there are $m$ different intermediate sectors. Output of the consumption good is $y_{t}=\sum_{i=1}^{m} A_{i t} F\left(x_{i t}\right)$, where $x_{i t}$ denotes the flow of output of the $i$ th intermediate good during interval $t$, and where $F$ has all the properties assumed above. (This requires that each sector have its own specialized brand of unskilled labor.)

Following Shleifer (1986), suppose that innovations arrive in different sectors in a deterministic order ${ }^{21}$ Specifically, the innovating sector is always the one with the lowest productivity parameter $A_{i t}$. Each innovator becomes a local monopolist in that sector for a period of $m$ successive innovations, and is replaced by the last of those $m$ innovations. Let $A_{t}$ denote the productivity parameter in the leading sector, where an innovation has arrived most recently. Assume that $A_{i t}=\gamma^{(1-k) / m} A_{t}$ when $i$ is the $k$ th most advanced sector. Then $\gamma$ is again the size of each innovation relative to the previous vintage of good in the same sector.

Let $\hat{x}_{k}$ denote the stationary-equilibrium employment of skilled labor in the $k$ th most advanced sector. Then $\hat{x}_{k}$ maximizes the flow of profits:

$$
\left[A_{t} \gamma^{(1-k) / m} F^{\prime}\left(x_{k}\right)-w_{t}\right] x_{k} .
$$

Therefore,

$$
\hat{x}_{k}=\tilde{x}\left(\gamma^{(k-1) / m} \omega\right),
$$

where $\tilde{x}$ is defined as above and $\omega$ is again the stationary-equilibrium productivity-adjusted wage, $w_{t} / A_{t}$. The productivity-adjusted flow of profits in the $k$ thleading sector is

$$
\pi_{t}^{k} / A_{t}=\gamma^{(1-k) / m} \tilde{\pi}\left(\gamma^{(k-1) / m} \omega\right)
$$

\footnotetext{
${ }^{21}$ The alternative of allowing innovations to be randomly distributed across sectors is analyzed in an Appendix to an earlier version of this paper, available from the authors upon request. This Appendix assumes a continuum of sectors and a continual flow of innovations. Whoever innovates at date $\tau$ is thereby allowed to enter a randomly chosen sector with the "leading technology" $A(\tau)$, where $A(\tau)$ grows continuously at the exponential rate $\sigma \lambda n$. The possibility that the same sector might receive two innovations in rapid succession, before the leading technology has advanced by much, implies that in stationary equilibrium some positive (and endogenous) fraction of innovations will be nondrastic. The model yields all the comparative-statics results of Proposition 1 above, except possibly for result (b).
} 
The productivity-adjusted wage is the solution to the equilibrium condition

$$
N=n+\sum_{k=1}^{m} \tilde{x}\left(\gamma^{(k-1) / m} \omega\right),
$$

which can be written as

$$
\omega=\hat{\omega}(N-n),
$$

where the function $\hat{\omega}$ satisfies Assumption 1 above.

Let the technology of research be the same as before, with an arrival parameter equal to $m \lambda$. The length of each interval is distributed exponentially with parameter $m \lambda \varphi(n)$, and each local monopoly lasts for $m$ intervals. Let $\tau_{t}$ denote the time of the $t$ th innovation. Then the value of the $t$ th innovation is

$$
\begin{aligned}
V_{t} & =\sum_{k=1}^{m} E\left(e^{-r\left(\tau_{t+k-1}-\tau_{t}\right)}\right)\left(\frac{\pi_{t+k-1}^{k}}{r+m \lambda \varphi(n)}\right) \\
& =A_{t} \sum_{k=1}^{m}\left(\frac{m \lambda \varphi(n)}{r+m \lambda \varphi(n)}\right)^{k-1}\left(\frac{\tilde{\pi}\left(\gamma^{(k-1) / m} \omega\right)}{r+m \lambda \varphi(n)}\right),
\end{aligned}
$$

and the condition for a positive stationary-equilibrium level of research is the analogue to (3.3):

$$
\frac{\hat{\omega}(N-\hat{n})}{m \lambda \varphi^{\prime}(\hat{n})}=\sum_{k=1}^{m}\left(\frac{m \lambda \varphi(\hat{n})}{r+m \lambda \varphi(\hat{n})}\right)^{k-1}\left(\frac{\gamma^{1 / m} \tilde{\pi}\left[\gamma^{(k-1) / m} \hat{\omega}(N-\hat{n})\right]}{r+m \lambda \varphi(\hat{n})}\right) .
$$

In the linear Cobb-Douglas example this condition is the analogue to (3.4):

$$
1=m \lambda\left(\frac{1-\alpha}{\alpha}\right)(N-n) \frac{\sum_{1}^{m} \gamma^{(k-1) / m(\alpha-1)}\left[\frac{\gamma^{k / m}(m \lambda \hat{n})^{k-1}}{(r+m \lambda \hat{n})^{k}}\right]}{\sum_{1}^{m} \gamma^{(k-1) / m(\alpha-1)}} .
$$

Since the right-hand side of (8.1) is a decreasing function ${ }^{22}$ of $n$ and the left-hand side an increasing function, the solution to (8.1), if it exists, is unique. If no solution exists, then the equilibrium level of research is zero. All the comparative-statics results of Proposition 1 apply to the solution of (8.1), with the possible exception of (b), the effect of $\gamma$, the size of innovations. In the

${ }^{22}$ Note that

$$
\begin{aligned}
\frac{\partial}{\partial n} \sum_{k=1}^{m} & \frac{(m \lambda \varphi(n))^{k-1} \tilde{\pi}_{k}}{(r+m \lambda \varphi(n))^{k}} \\
& =m \lambda \varphi^{\prime}(n) \sum_{k=1}^{m}\left\{\frac{(k-1)(m \lambda \varphi(n))^{k-2} \tilde{\pi}_{k}}{(r+m \lambda \varphi(n))^{k}}-\frac{k(m \lambda \varphi(n))^{k-1} \tilde{\pi}_{k}}{(r+m \lambda \varphi(n))^{k+1}}\right\} \\
& =m \lambda \varphi^{\prime}(n) \sum_{k=2}^{m+1} \frac{(k-1)(m \lambda \varphi(n))^{k-2}\left(\tilde{\pi}_{k}-\tilde{\pi}_{k-1}\right)}{(r+m \lambda \varphi(n))^{k}}<0,
\end{aligned}
$$

where $\tilde{\pi}_{1}>\tilde{\pi}_{2}>\cdots>\tilde{\pi}_{m}>\tilde{\pi}_{m+1} \equiv 0$. 
linear Cobb-Douglas example, however, it can be shown that (b) remains true, provided that the social discount rate (the denominator of $U$ below) is positive. ${ }^{23}$

In stationary equilibrium each innovation raises the entire cross-sectional profile of productivity parameters by the factor $\gamma^{1 / m}$. It therefore raises GNP by $\gamma^{1 / m}$, and raises the $\log$ of GNP by the factor $(1 / m) \ln \gamma$. Since the Poisson arrival rate of innovation is $m \lambda \hat{n}$, therefore the economy's average growth rate is $\lambda \hat{n} \ln \gamma$, exactly as before. The variance of the growth rate is $\lambda \hat{n}(\ln \gamma)^{2} / m$; aggregation across many sectors reduces variability through a law of large numbers.

By the same logic as in Section 4, social welfare is measured by

$$
U=A_{0} \frac{\sum_{1}^{m} \gamma^{(1-k) / m} F\left(x_{k}\right)}{r-m \lambda \varphi(n)\left(\gamma^{1 / m}-1\right)} .
$$

A social planner would choose $\left(x_{1}, \ldots, x_{m}, n\right)$ to maximize $U$ subject to the constraint,

$$
N-n=x_{1}+\cdots+x_{m},
$$

and $n \geqslant 0$. The first-order conditions for an interior maximum are

$$
F^{\prime}\left(x_{k}\right)=\mu \gamma^{(k-1) / m} \quad(k=1, \ldots, m),
$$

where $\mu$ is a Lagrange multiplier. Let $\hat{\mu}(N-n)$ denote the value of $\mu$ such that the solutions $\left(x_{1}, \ldots, x_{m}\right)$ to (8.4) solve (8.3). Then (8.5) can be expressed as:

$$
\frac{\hat{\mu}\left(N-n^{*}\right)}{m \lambda \varphi^{\prime}\left(n^{*}\right)}=\sum_{k=1}^{m}\left(\gamma^{-1 / m}\right)^{k-1}\left(\frac{\left(\gamma^{1 / m}-1\right) F\left(x_{k}^{*}\right)}{r-m \lambda \varphi\left(n^{*}\right)\left(\gamma^{1 / m}-1\right)}\right) \text {. }
$$

In the linear Cobb-Douglas example,

$$
1=\frac{m \lambda\left(\frac{1}{\alpha}\right)\left(\gamma^{1 / m}-1\right)\left(N-n^{*}\right)}{r-m \lambda n^{*}\left(\gamma^{1 / m}-1\right)} .
$$

Comparison of (8.6) with (8.1) reveals the same four effects as before. The monopoly-distortion effect is still present because $\hat{\mu}(N-n)>\hat{\omega}(N-n)$. The

${ }^{23}$ It suffices to show that the right-hand side of (8.2) is increasing in $\gamma$. The ratio of sums in this expression can be regarded as the expected value of the discrete random variable

$$
z_{k} \equiv\left[\frac{\gamma^{1 / m}}{1+r / m \lambda n}\right]^{k} / m \lambda n,
$$

under the truncated geometric distribution with parameter $\gamma^{1 / m(\alpha-1)}<1$. The effect on this ratio of a marginal increase in $\gamma$ is the sum of the effect on each $z_{k}$ and the effect of changing the parameter of the distribution. The former is positive. The latter would also be positive, by first-order stochastic dominance, if $z_{k}$ were decreasing in $k$, which it is if the social discount rate is positive. 
appropriability effect applies sector-by-sector, and is amplified by the fact that

$$
\gamma^{-1 / m}>\left(\frac{m \lambda \varphi(n)}{r+m \lambda \varphi(n)}\right)
$$

if the social discount rate is positive. As before, research and growth under laissez-faire may be more or less than optimal; in the linear Cobb-Douglas example, $\hat{n}<n^{*}$ if $\gamma$ is large, ${ }^{24}$ but $\hat{n}>n^{*}$ if $\alpha$ is small and $\gamma$ is not too large. ${ }^{25}$

\title{
9. CONCLUSION
}

The paper has presented a model of economic growth based on Schumpeter's process of creative destruction. Growth results exclusively from technological progress, which in turn results from competition among research firms that generate innovations. Each innovation consists of a new intermediate good that can be used to produce final output more efficiently than before. Research firms are motivated by the prospect of monopoly rents that can be captured when a successful innovation is patented. But those rents in turn will be destroyed by the next innovation, which will render obsolete the existing intermediate good.

It would be useful to generalize and extend the analysis in several directions, such as assuming that technology is ultimately bounded, thereby requiring the size of innovations eventually to fall. The model would gain richness and realism if capital were introduced, either physical or human capital embodying technical change, or R and D capital that affects the arrival rate of innovations. Allowing unemployment, by introducing search into the labor market, would facilitate study of the reciprocal interaction between technological change and the business cycle. All these extensions seem feasible because of the simplicity and transparency of the basic model.

European Bank for Reconstruction and Development, 122 Leadenhall St., London EC3 V4QL, U.K.

\section{and}

Department of Economics, The University of Western Ontario, London, Ontario N6A 5C2, Canada

Manuscript received June, 1989; final revision received July, 1991.

\author{
APPENDIX 1 \\ AN EXAMPLE WITH A RANDOM ARRIVAL PARAMETER
}

Let $\lambda$ follow a two-state Markov process on the space $\left\{\lambda_{1}, \lambda_{2}\right\}$ with all transition probabilities equal to $1 / 2$. A stationary equilibrium is an equilibrium in which the productivity-adjusted wage rate depends only on the state of the world, not on time. Let $A_{t} V_{j}$ be the value of making the $t$ th

\footnotetext{
${ }^{24}$ From (8.7), as $\gamma^{1 / m}$ rises to the upper limit $1+r / m \lambda N, n^{*}$ approaches $N$ while, from (8.2), $\hat{n}$ is bounded below $N$.

${ }^{25}$ If $1 / \alpha>1+r / \lambda N$ then $\hat{n}>0$ for all $\gamma$, whereas if $\gamma^{1 / m} \leqslant 1+\alpha r / m \lambda N$, then $n^{*}=0$.
} 
innovation and moving into state $j$. Assume the linear case of $\varphi(n)=n$. In any state $i$, the marginal expected return to research in interval $t$ is $\lambda_{i} A_{t+1}\left(V_{1}+V_{2}\right) / 2$. This will equal the wage if positive research occurs in state $i$. If research occurs in all states, the $V_{i}$ 's must satisfy the analogue to (2.12):

$$
V_{i}=\frac{\tilde{\pi}\left(\lambda_{i} \gamma\left(V_{1}+V_{2}\right) / 2\right)}{r+\lambda_{i}\left[N-\tilde{x}\left(\lambda_{i} \gamma\left(V_{1}+V_{2}\right) / 2\right)\right]}
$$

Define $n_{i} \equiv N-\tilde{x}\left(\lambda_{i} \gamma\left(V_{1}+V_{2}\right) / 2\right)$. Then the average level of research employment is

$$
\bar{n}=n_{1} q_{1}+n_{2} q_{2}
$$

where $q_{i}$ is the asymptotic fraction of time spent in state $i$. It is easily verified that

$$
q_{1}=1-q_{2}=\lambda_{2} n_{2} /\left(\lambda_{1} n_{1}+\lambda_{2} n_{2}\right) .
$$

To complete the example, take the Cobb-Douglas case $\left(F(x)=x^{\alpha}\right)$, and suppose $\alpha=\gamma^{-1}=1 / 2$ and $r=N=\lambda_{1}=1$. Since $\tilde{x}(\omega)=\left(\omega / \alpha^{2}\right)^{1 /(\alpha-1)}$ and $\tilde{\pi}(\omega)=((1-\alpha) / \alpha) \omega \tilde{x}(\omega)$, the formula for each $V_{i}$ can be rewritten as:

$$
V_{1}=\left[16\left(V_{1}+V_{2}\right)\right]^{-1}-\left\{1-\left[4\left(V_{1}+V_{2}\right)\right]^{-2}\right\} V_{1},
$$

and

$$
V_{2}=\left[16 \lambda_{2}\left(V_{1}+V_{2}\right)\right]^{-1}-\lambda_{2}\left\{1-\left[4 \lambda_{2}\left(V_{1}+V_{2}\right)\right]^{-2}\right\} V_{2} .
$$

When $\lambda_{2}=1$, the solution to these equations is $V_{1}=V_{2}=\sqrt{3} / 8 \sqrt{2}$, which implies $n_{1}=n_{2}=\bar{n}=1 / 3$. As $\lambda_{2} \rightarrow \infty$, the solution approaches $V_{1}=1 / 4, V_{2}=0$, which implies $n_{1}=0, n_{2}=1$, and $q_{1}=$ $n_{2} /\left(n_{2}+\lambda_{1} n_{1} / \lambda_{2}\right)=1$; hence $\bar{n}=0$.

The economy's average growth rate equals $f \ln \gamma$, where $f$ is the asymptotic frequency of innovations:

$$
f=\lambda_{1} n_{1} q_{1}+\lambda_{2} n_{2} q_{2}=\left[\frac{2 \lambda_{1} \lambda_{2}}{\lambda_{1}+\lambda_{2}}\right] \bar{n} .
$$

Thus when $\lambda_{2}=1, f \ln \gamma=(1 / 3) \ln 2>0$; and as $\lambda_{2} \rightarrow \infty, f \ln \gamma$ approaches 0 .

\section{APPENDIX 2}

\section{DERIVATION OF CONDITION (5.5)}

In the stationary equilibrium described in Section 5, the monopolist has no incentive to do research if

$$
w_{t} \geqslant \lambda\left(V_{t+1}^{M}-V_{t}\right)
$$

where

$$
V_{t}=\frac{\left(\gamma^{1 / \alpha}-1\right) w_{t}(N-\hat{n})}{r+\lambda \hat{n}}
$$

is the value of the monopolist's current patent and

$$
V_{t+1}^{M}=\frac{\left[\min \left(\gamma^{2 / \alpha}, \alpha^{-1}\right)-1\right] w_{t+1}(N-\hat{n})}{r+\lambda \hat{n}}
$$

would be the gross value of the next innovation to the current monopolist, for whom the innovation would be drastic if $\gamma^{2}>\alpha^{-\alpha}$, if next period the level of research was the stationary-equilibrium value $\hat{n}$. In fact more than this level of research would be conducted if the monopolist were to innovate, because the monopolist could then charge a markup higher than $\gamma^{1 / \alpha}$, so the value would actually be less than $V_{t+1}^{M}$. Substituting these expressions for $V_{t}$ and $V_{t+1}^{M}$ into (A.1) and using the 
fact that $w_{t+1}=\gamma w_{t}$ produces

$$
1 \geqslant \frac{\lambda\left[\gamma \min \left(\gamma^{2 / \alpha}, \alpha^{-1}\right)-\gamma-\left(\gamma^{1 / \alpha}-1\right)\right](N-\hat{n})}{r+\lambda \hat{n}} .
$$

Condition (5.5) follows immediately from (A.2) and (5.7).

\section{REFERENCES}

Aghion, P., AND P. Howitt (1988): "Growth and Cycles through Creative Destruction," Unpublished, University of Western Ontario.

AzARIAdis, C. (1981): “Self-Fulfilling Prophecies," Journal of Economic Theory, 25, 380-396.

Corriveau, L. (1988): "Entrepreneurs, Growth, and Cycles," Unpublished, University of Western Ontario.

Deneckere, R. J., AND K. L. Judd (1986): "Cyclical and Chaotic Behavior in a Dynamic Equilibrium Model, with Implications for Fiscal Policy," Unpublished, Northwestern University.

Dixit, A., ANd J. Stiglitz (1977): "Monopolistic Competition and Optimum Product Diversity," American Economic Review, 67, 297-308.

Grandmont, J.-M. (1985): “On Endogenous Competitive Business Cycles,” Econometrica, 53, 995-1045.

Grossman, G. M., and E. Helpman (1991): "Quality Ladders in the Theory of Growth," Review of Economic Studies, 58, 43-61.

JudD, K. L. (1985): "On the Performance of Patents," Econometrica, 53, 567-585.

King, R. G., AND S. T. Rebelo (1988): "Business Cycles with Endogenous Growth," Unpublished, University of Rochester.

Lerner, A. P. (1934): “The Concept of Monopoly and the Measurement of Monopoly Power," Review of Economic Studies, 1, 157-175.

LuCAS, R. E. JR. (1988): “On the Mechanics of Economic Development," Journal of Monetary Economics, 22, 3-42.

Mortensen, D. T. (1982): "Property Rights and Efficiency in Mating, Racing and Related Games," American Economic Review, 72, 968-979.

ReInganum, J. (1985): “Innovation and Industry Evolution,” Quarterly Journal of Economics, 100, 81-99.

(1989): "The Timing of Innovation: Research, Development and Diffusion," in Handbook of Industrial Organization, Vol. I, ed. by R. Schmalensee and R. Willig. Amsterdam: North-Holland.

Romer, P. M. (1986): "Increasing Returns and Long-Run Growth,” Journal of Political Economy, 94, $1002-1037$.

- (1990): “Endogenous Technological Change," Journal of Political Economy, 98, S71-S102.

SCHERER, F. M. (1984): Innovation and Growth: Schumpeterian Perspectives. Cambridge, MA: MIT Press.

Schumpeter, J. A. (1942): Capitalism, Socialism and Democracy. New York: Harper and Brothers.

Segerstrom, P. S., T. C. A. Anant, and E. Dinopoulos (1990): “A Schumpeterian Model of the Product Life Cycle," American Economic Review, 80, 1077-1091.

Shleifer, A. (1986): "Implementation Cycles," Journal of Political Economy, 94, 1163-1190.

Stokey, N. L. (1988): "Learning by Doing and the Introduction of New Goods," Journal of Political Economy, 96, 701-717.

TiRole, J. (1988): The Theory of Industrial Organization. Cambridge, MA: M.I.T. Press. 